\title{
Funções enunciativas do discurso sobre a Educação de Jovens e Adultos (EJA) no Curso de Pedagogia da UFPB
}

\author{
Marcos Angelus Miranda de Alcantara \\ Erenildo João Carlos \\ Universidade Federal da Paraíba
}

\section{Resumo}

Este estudo investigou o enunciado da EJA no Curso de Pedagogia da UFPB. Tendo em vista que a Análise Arqueológica do Discurso foi utilizada como abordagem, o discurso foi investigado como uma série de signos apoiados em uma formação discursiva (FOUCAULT, 2008). O Projeto Político-pedagógico do Curso (UFPB, 2006) foi o corpus empírico. Os resultados apontam três séries enunciativas: direito à educação, saberes e sujeitos. A primeira mobiliza o signo da institucionalidade; a segunda aponta para o campo epistêmico; a última evidencia a formação e a atuação do pedagogo. Portanto, este estudo explica de que modo a EJA se constitui como um campo do saber na formação do pedagogo.

Palavras chave: Educação de jovens e adultos. Curso de Pedagogia. Análise arqueológica do discurso.

\section{Enunciative functions of the discourse on Youth and Adult Education (YAE) in UFPB's Pedagogy Course}

\section{Abstract}

This study investigated the enunciation of YAE in the Pedagogy Course of UFPB. Considering that The Archaeological Discourse Analysis was used as an approach, the research dealt with the investigation as a series of signs supported in the discursive formation speech (FOUCAULT, 2008). The empirical corpus was the Political-Pedagogical Project of the Course (UFPB, 2006). The results show that the three enunciative series: the right to education, knowledge and individuals positions. The first one mobilizes the sign of the institutionalization; the second point to the epistemic field; the last one evidences the formation and action of the pedagogue. Therefore, this study explains how the YAE has been constituted as a field formative of the pedagogue.

Keywords: Youth and adults education. Pedagogy course. Archaeological discourse analysis. 


\section{Funciones enunciativas del discurso sobre la Educación de Jóvenes y Adultos (EJA) en el Curso de Pedagogía de la UFPB}

\section{Resumen}

Este estudio investigó el enunciado de la EJA en el Curso de Pedagogía de la UFPB. Teniendo en vista que el Análisis Arqueológica del Discurso fue utilizado como abordaje, el discurso fue investigado como una serie de signos apoyados en una formación discursiva (FOUCAULT, 2008). El Proyecto Político-pedagógico del Curso (UFPB, 2006) fue el corpus empírico. Los resultados apuntan tres series enunciativas: directo a la educación, saberes y sujetos. La primera, moviliza el signo de la institucionalidad; la segunda, apunta para el campo epistémico; la última, evidencia la formación y la actuación del pedagogo. Por lo tanto, este estudio explica de qué manera la EJA se constituye como un campo del saber en la formación del pedagogo.

Palabras clave: Educación de jóvenes y adultos. Curso de Pedagogía. Análisis del discurso arqueológico.

\section{Introdução}

A atuação do pedagogo na Educação de Jovens e Adultos (EJA) abrange três grandes possibilidades: o ensino, a pesquisa e a gestão. Evidentemente, cada área não é isolada em si mesma. Acerca da EJA, Beisiegel (2008) e Brandão (2008), entre outros, asseguram que existe um acúmulo de experiências construídas fora do espaço escolar. É possível afirmar que foi forjado um modelo pedagógico pautado no que hoje é denominado de Educação Popular. Essas experiências, iniciadas nos anos 1960, são marcadas pelo estímulo ao diálogo no processo educativo (BEISIEGEL, 2008). Tal período é classificado como fértil e de intensa militância política através da educação (BRANDÃO, 2008).

Em conformidade com esse pensamento, é possível afirmar que a EJA, com todas as experiências forjadas nos movimentos populares, é um saber/ enunciado constituinte do pedagogo que pretende atuar nessa modalidade, seja na área do ensino, na gestão ou na pesquisa em educação. A questão aqui colocada, porém, é o modo como a EJA, se constitui enunciativamente no Curso de Pedagogia, especificamente na Universidade Federal da Paraíba 
(UFPB) - Campus I, situada em João Pessoa. Essa problemática impôs a necessidade de se fazer uma incursão pela produção acadêmica sobre a EJA. Em geral, essas pesquisas a afirmam como uma conquista histórica que marca a década de 1990, com a LDB n 9.394/96, quando a EJA passou a ser reconhecida como modalidade (AZEVEDO, 2002; MARQUES, 2010; DI PIERRO, 2010).

Embora essas pesquisas afirmem a importância de se pensar a EJA no espaço escolar, parte significativa ocupou-se da investigação de políticas ou experiências, isto é, há um relativo vazio no que diz respeito à questão do campo teórico/prático da EJA na formação do pedagogo, sobretudo quando o problema se desloca para o discurso. É nesse espaço em que a importância dessa problemática é afirmada. Trata-se de pensar como a EJA está constituída enunciativamente no Curso de Pedagogia. Isso impôs a necessidade de recorrer a um tipo de acúmulo mais específico - as produções em EJA que fazem aparecer o discurso, seja como objeto, como fonte de pesquisa ou como abordagem teórico-metodológica.

Com esse segundo levantamento, foi possível identificar que o discurso tem se constituído como objeto de investigação na EJA, através de abordagens, referências e concepções distintas, a saber: 1 - opiniões de grupos ou indivíduos: nesse caso, as pesquisas recorrem a entrevistas dirigidas a alunos ou a professores, para compreender o que eles têm a dizer sobre dada prática educativa (RUOTTI, 2008); 2 - as produções textuais dos educandos: são as pesquisas que analisam as atividades escritas produzidas por alunos da EJA (ARRUDA, 2010); 3 - o discurso sobre a formação docente em EJA: essas pesquisas buscam compreender, de modo geral, que aspectos formativos estão presentes nas falas dos entrevistados (ALMEIDA, 2008); 4 - a antítese das práticas, que comparam as coisas ditas às realizadas. Geralmente recorrem às análises documentais, a entrevistas e a observações empíricas (CANTANHEDE, 201 11; 5 - correlações entre enunciados: procuram explicar as coisas ditas em nível enunciativo. Elas descrevem os campos de coexistência dos discursos, as relações que a ordem discursiva põe em funcionamento, enfim, produzem explicações sobre os modos de existência e constituição de um dado Saber (CARLOS, 2005; MARQUES, 2010; SANTOS, 2011 ).

De certo modo, é nesse quinto grupo que esta pesquisa esteve situada teórica e metodologicamente. Consequentemente, distanciou-se de outras abordagens que demarcam entendimentos e procedimentos distintos acerca 
da noção de discurso. Conforme Alcantara e Carlos (2013), a Análise Arqueológica do Discurso (AAD) é uma abordagem que oferece uma série de ferramentas específicas à produção do conhecimento, em uma perspectiva enunciativa, no campo da EJA. Nessa direção, os enunciados são comparados aos artefatos materiais identificados pelos arqueólogos em suas escavações.

Tendo em vista se realizar, metodicamente, em cada fase do processo investigativo, a análise do objeto em questão, selecionaram-se, em Foucault (2008) alguns conceitos operativos. De maneira sucinta, são eles: o discurso - uma série de enunciados apoiados em uma mesma formação discursiva; o enunciado - o modo de existência do signo. É possível dizer que a condição de existência de um enunciado é a relação que ele estabelece com outro enunciado; o sujeito - "[...] uma função determinada [...] na medida em que é uma função vazia, podendo ser exercida por indivíduos [...]" distintos uns dos outros (FOUCAULT, 2008, p. 105); os campos de domínio - o cenário de coexistências discursivas; e a materialidade - o status conferido ao enunciado, ou seja, seu aparecimento em uma dada ordem discursiva. Não obstante,

[... e é necessário esclarecer, primeiramente, que, ao recorrer à $A A D$ como ferramenta, não temos a intenção de analisar a EJA como um acontecimento situado no campo da História da Educação, de compreendê-la a partir de concepções ideológicas, políticas, pedagógicas ou, ainda, de comparar o que se diz com o que se faz na EJA. Em outras palavras, não se emprega a AAD como uma técnica para se realizar um estudo preocupado com as teorias de currículo, com as práticas educativas, com a trajetória histórica da EJA ou a distância entre a proposta e sua efetividade. Com efeito, embora o conhecimento do discurso possibilite a compreensão de alguns desses fatores, a AAD não se ocupa em fazer uma pesquisa de natureza empírica [...] (ALCANTARA; CARLOS, 2013, p. 69).

A investigação partiu da determinação do objeto ao enunciado da EJA presente no Curso de Pedagogia da UFPB/Campus I (João Pessoa), que propiciou a formulação da seguinte questão/problema: como a EJA está constituída enunciativamente no Curso de Pedagogia da UFPB/campus I (João Pessoa)? Tendo em vista tanto o objeto quanto o problema, foram estabelecidos os seguintes objetivos: geral - Analisar o enunciado da EJA no Curso de Pedagogia da UFPB/Campus I (João Pessoa). Específicos - Mapear os documentos relacionados à EJA, que constam no PPP de Pedagogia da UFPB/campus I Uoão 
Pessoa); escavar os artefatos enunciativos que constituem o discurso da EJA no Curso de Pedagogia; situar, nessa ordem discursiva, as concepções de prática educativa e de formação em EJA, assumidas pelo Curso de Pedagogia; explicar o posicionamento dos alunos de Pedagogia, produzido na ordem do discurso em questão; e, por fim, contribuir para o entendimento crítico sobre as coisas ditas a respeito da EJA no Curso de Pedagogia.

Seguindo o que foi estabelecido no primeiro objetivo específico, este estudo se deparou com o Projeto Político-pedagógico (PPP) do Curso de Pedagogia (2006) da UFPB/campus I (João Pessoa), e uma série de outros documentos nele referenciados 1 . À luz dos conceitos adotados, foi realizada a leitura e a análise desses documentos, em busca de expressões, palavras-chave e frases que tivessem relação com o objeto da pesquisa, o que possibilitou identificar e mapear, em linhas gerais, como o enunciado da EJA era constituído no Curso de Pedagogia, dando conta do que foi estabelecido no segundo objetivo específico. Com relação aos demais objetivos, ao sistematizar e ordenar os "achados", a pesquisa conferiu visibilidade à especificidade das regras de funcionamento do discurso investigado. Ou seja, assim como as peças de um artefato material que estão soterradas e dispersas no tempo e no espaço, o processo de escavação seguido de análise, possibilitou a construção de explicações a respeito do modo como essas peças se articulam, a partir de seus próprios formatos e modos de existência (ALCANTARA e CARLOS, 2013).

Deste modo, foi possível conhecer como se constitui o enunciado da EJA, presente no Curso de Pedagogia da UFPB/Campus I (João Pessoa). É o que os próximos tópicos apresentam mais detalhadamente. Trata-se dos achados resultantes da investigação, a partir de três funções enunciativas identificadas, mapeadas e descritas: o direito à educação, os saberes e as posições dos sujeitos.

\section{A função enunciativa do direito à educação}

Este tópico demonstra como os enunciados constitutivos do Direito se deslocam para o campo educacional. Nessa direção, o Direito segue, até certo ponto, o esquema da dialética hegeliana da tese, da antítese e da síntese (REALE, 1998). O fato seria análogo à tese; já o valor não seria exatamente seu contrário, a antítese. Na modalidade do discurso educacional, as experiências 
educativas são identificadas como fato; a educação, como valor; e o ordenamento jurídico educacional, como norma. Observou-se esse movimento nos discursos oficiais, que enunciam a institucionalidade da EJA. De semelhante modo, no tensionamento que existe, permanentemente, entre o caráter oficial do direito institucional à educação e a ordem discursiva dos grupos e movimentos sociais populares. Esses, historicamente, defendem a garantia e a efetividade do direito à educação para todos, resguardando as especificidades de cada sujeito social, como os jovens e os adultos analfabetos, sem escolarização ou semi-escolarizados, por exemplo.

Mediante o processo investigativo, que recorreu ao PPP de Pedagogia da UFPB/Campus I (João Pessoa) e uma série de textos nele referenciados, é possível afirmar que a função enunciativa do Direito à Educação, no discurso da EJA, está constituída pelas seguintes séries de enunciados: 1 - o Estado brasileiro e a EJA; 2 - a Institucionalidade da EJA; 3 - Os valores sociais presentes no direito à educação; 4 - o posicionamento da sociedade civil frente à problemática da EJA.

Em relação à primeira série enunciativa presente no direito à educação - o Estado brasileiro - há três séries de signos marcantes: o projeto nacional, 158 o ajustamento social e a política educacional. $\bigcirc$ signo projeto nacional evoca a marca do engajamento de todos os indivíduos, grupos e segmentos sociais comprometidos com o desenvolvimento nacional. Nessa direção, o discurso sobre a EJA é vinculado a um ideário, que promove "[...] um movimento nacional de mobilização de recursos de organizações públicas a particulares e de todos os indivíduos [...] na implantação e no desenvolvimento da educação do adulto" (BEISIEGEL, 1974, p. 152). É necessário, para esse discurso, que a nação brasileira faça esse esforço "[...] em prol de uma igualdade de acesso à educação como bem social [...]" necessária aos brasileiros que a ela não tiveram acesso (BRASIL, 2000, p. 22).

Por sua vez, o signo do ajustamento social indica uma perspectiva de adaptação dos indivíduos ao contexto nacional, ao mesmo tempo que se busca sanar os "distúrbios sociais". Assim, afirma-se que, como a sociedade é harmônica, percebeu-se, diante de alguns eventuais distúrbios sociais, a necessidade de apoiar a educação destinada a adultos. Embora esse discurso pareça datado da primeira metade do Século XX, ainda é objeto de contestação, crítica e negação no campo de domínio da EJA. As interdiç̃̃es aparecem à medida que esses enunciados posicionam a sociedade como um organismo 
sadio, harmônico e perfeito. Uma das maiores críticas a isso reside na vinculação dessa série enunciativa de "ajuste social" a discursos dominadores, alienantes e desumanizantes (FREIRE, 1981).

Por fim, o signo da política educacional diz respeito ao conjunto de ações institucionais articuladas que visam, a um só tempo, ao desenvolvimento humano, social e econômico no país. Nessa ordem discursiva, as políticas educacionais, voltadas para os jovens e os adultos, devem primar por objetivos que desenvolvam a "[...] capacidade de lidar com as transformações que ocorrem na economia $[\ldots]$ " como também no próprio modelo econômico e de mercado (SESI/UNESCO, 1999, p. 2). Essa relação enunciativa entre políticas educacionais e equalização social ajuda a sustentar "[...] a hipótese de que a educação é uma condição não apenas necessária, mas também suficiente para a resolução dos problemas sociais enfrentados no país" (MATENCIO, 1995, p. 246).

A segunda série enunciativa - a institucionalidade da EJA - também é constituída por algumas séries de signos: a Educação Básica, a modalidade EJA e a instituição escolar. $O$ signo da 'educação básica' posiciona a EJA como uma de suas modalidades em duas etapas: Ensino Fundamental e Ensino Médio. Trata-se "[...] do reconhecimento formal da importância do ensino fundamental e médio e de sua universalização dentro da escola com a oferta de ensino regular" (BRASIL, 2000, p. 58). Isso cria as condições enunciativas de se afirmar o lugar da EJA, tanto na fase inicial da Educação Básica quanto na final. Esse processo deve

[...] habilitar ao prosseguimento de estudos em caráter regular (art. 38 da (DB). Em outras palavras, os estudantes da EJA também devem se equiparar aos que sempre tiveram acesso à escolaridade e nela puderam permanecer (BRASIL, 2000, p. 27).

Ao tomar a forma de Educação Básica, a EJA passa a ser um modo de existência desse nível educacional, em outras palavras, uma Modalidade da Educação Básica - o segundo signo. A EJA, posicionada como uma "[...] modalidade [...] é regular [...]" (BRASIL, 2000, p. 30). Isso supera a comum dualidade entre "ensino regular e EJA", tão presente nos discursos midiáticos e políticos. Ao assumir tal condição de regularidade, o campo de domínio da EJA rompe com o enunciado da externalidade à Educação Básica e ao sistema, consolidando sua institucionalidade como um direto social destinado àqueles 
que, ao longo de sua trajetória pessoal e social, passaram por situações excludentes ou de vulnerabilidade social, e, por isso, não frequentaram a escola.

terceiro signo acionado nessa função enunciativa é a instituição escolar. Trata-se de uma agência que faz parte da cultura moderna e contemporânea, intrinsecamente vinculada à trajetória do pensamento ocidental, com suas influências nos discursos institucionais postos para a educação (COMENIUS, 2001). Os enunciados específicos ao seu funcionamento são: sua rotina, seus profissionais, seu espaço físico, sua carga horária, o calendário letivo etc. Coexistindo com essa configuração, há o discurso da EJA, cuja trajetória histórica, política e pedagógica foi quase toda forjada à margem desse esquema clássico que legitima o sistema escolar oficial. A EJA é marcada por signos como movimentos populares, ONGs, projetos de extensão popular, entre outros. São territórios demarcados em torno de outros discursos, como a luta por terra, moradia, trabalho, enfim, uma cultura militante. A correlação entre a EJA e o espaço escolar propõe uma síntese entre esses dois enunciados. Nem a EJA será exatamente a mesma, em função da especificidade da instituição, nem a escola será a mesma em função do campo de domínio da EJA.

A terceira série enunciativa constitutiva dessa função - os valores 160 aciona os seguintes signos: a humanização, a democracia e a libertação. $\bigcirc$ signo da humanização evoca o ser humano como ente que se destaca entre os demais seres vivos. Nessa perspectiva, "[...] ao dizer a sua palavra, pois, o homem assume conscientemente sua essencial condição humana" (FREIRE, 1981 , p. 7). $\bigcirc$ ato educativo, nesse discurso, está profundamente vinculado a signos como a palavra, a crença a amorosidade etc. Trata-se de estar convencido de que "[...] a educação, que deve ser um ato coletivo, solidário - um ato de amor - [...] não pode ser imposta" (BRANDÃO, 1981, p. 22). Essa relação entre a educação, a palavra, a crença e o amor faz do homem um ser permanentemente apto ao ato educativo. É o enunciado da busca ontológica, histórica e cotidiana, que não está com data prevista para ser concluída.

signo da democracia funciona como um valor que confere visibilidade à necessidade da formação de cidadãos, "[...] jovens e adultos brasileiros, participantes e comprometidos com uma sociedade justa, equânime e igualitária" (BRASIL, 2005, p. 16). Esse signo possibilita a afirmação de uma educação capaz de instrumentalizar o jovem e o adulto para a "[...] participação na vida política na Nação" (PAIVA, 1987, p. 213). É um discurso que desafia os indivíduos a assumir uma posição ativa no processo histórico. 
Além dessas possibilidades abertas, a apropriação de um conjunto de saberes, conhecimentos e habilidades, o processo educativo possibilitará uma participação mais ativa na vida política e social de sua comunidade, organização sindical, igreja, movimento social, entre outros.

Esse processo educativo, marcado por elementos como engajamento dos sujeitos em prol de uma sociedade mais democrática, caminha em uma perspectiva que aciona o signo da libertação, o terceiro artefato constitutivo da série enunciativa dos valores presentes no direito à educação. $\bigcirc$ signo da libertação não abre mão de seu caráter dialético, isto é, das contradições que forjam seu modo ser, seus princípios básicos de existência. Em Pedagogia do Oprimido, há uma reflexão acerca da "[...] libertação [que] desafia, de forma dialeticamente antagônica, a oprimidos e a opressores" (FREIRE, 1981, p. 11 1). Trata-se, no final das contas, de um discurso humano e humanizante, de uma busca que não é apenas histórica, mas também ontológica, marcada por enunciados como a transcendência da própria consciência, a fim de conhecer e estabelecer novas relações sociais, políticas, gnosiológicas, enfim, humanas.

Finalmente, a quarta série enunciativa, presente no direito à educação, constitui-se dos seguintes signos: os movimentos sociais, o contexto social e as classes sociais. A região enunciativa que posiciona os movimentos sociais como agentes da luta pelo direito à educação menciona diversas experiências educativas, conduzidas por movimentos populares. $O$ contorno da identidade desses movimentos é marcado por elementos como a valorização da cultura popular, a oposição a regimes políticos autoritários e a militância no campo dos direitos políticos, civis e sociais. Entre os articulados à problemática e às experiências de EJA, pode-se citar o Fórum EJA Brasil e os demais fóruns espaIhados pelos estados brasileiros. Particularmente no estado da Paraíba, o Fórum EJA da Paraíba. Conforme Silva (2003), trata-se de uma nova configuração em movimentos sociais e destaca-se com sua organização interinstitucional, há mais de uma década, debatendo e problematizando as questões relacionadas à educação de adultos nesse estado.

O signo do contexto social, acionado nessa série enunciativa da sociedade civil, emerge no Curso de Pedagogia com a criação de uma "[...] área de aprofundamento em Educação de Jovens e Adultos [...] [que] considerou a necessidade de [...] levar em conta as prioridades relativas ao grau de pertinência social [...]" dessa modalidade (UFPB, 2006, p. 6). Essa é "[...] uma abordagem do problema educativo em conexão com os problemas da 
sociedade [...]" (PAIVA, 1987, 250). Questões como a relação entre alfabetização, escolarização, a educação dos movimentos sociais e a situação política e econômica do país são artefatos enunciativos que, devidamente articulados, armam o esquema discursivo da EJA. É por causa dessas múltiplas relações, no processo de alfabetização, que as palavras "[...] são também instrumentos de releitura coletiva da realidade social onde a língua existe, e existem os homens que a falam e as relações entre os homens" (BRANDÃO, 1981, p. 31 ). Aqui a EJA é elevada à condição de requisito para modificar a estrutura social e política, ao disseminar um espírito democrático, coletivo e participativo, que altera a lógica marcada por signos como autoritarismo, individualismo, preconceito, analfabetismo e exclusão.

Fechando essa série enunciativa, o signo das classes sociais emerge na situação dialética, em que uma classe, para existir como tal, não pode abrir mão da existência da outra. Acerca disso, Freire (1981, p. 151) afirma que "[...] não há nada, contudo, de mais concreto e real do que a luta dos [...] homens com os homens, como também alguns homens contra homens, enquanto classes que oprimem e classes oprimidas". A educação, nessa perspectiva, é acionada como um elemento enunciativo que não é neutro. Ela pode 162 ser definida a favor de uma classe ou de outra. Servindo às classes populares, necessariamente, ela tem a tarefa de promover a consciência de classe.

discurso da EJA que está presente no Curso de Pedagogia se opõe a outros discursos que legitimaram a reserva da formação profissional apenas "[...] às classes menos favorecidas, estabelecendo-se uma nítida distinção entre aqueles que detinham o Saber [...] e os que executavam tarefas manuais [...]" (BRASIL, 1999, p. 06). Nesse campo de domínio da EJA no Curso de Pedagogia, a valorização do trabalho intelectual não pode se converter em uma estratégia de desqualificação do trabalho braçal ou manual. Caso isso não seja objeto de críticas, questionamentos e interdições, ratifica-se a lógica, segundo a qual os "[...] trabalhadores sempre foram relegados a uma condição social inferior" (BRASIL, 1999, p. 06).

\section{A função enunciativa dos Saberes}

Além de suas correlações com o domínio do Direito, o discurso da EJA é constituído pela função enunciativa dos saberes, a partir das seguintes séries: 
1 - Educação Popular (cultura, saberes populares, diálogo e conscientização); 2 - Conhecimento la pesquisa como via de produção do conhecimento científico na EJA, as especificidades da EJA); e 3 - Saberes pedagógicos (didática, cognição, planejamento e alfabetização). $\bigcirc$ percurso investigativo realizado nesse terreno possibilita a explicação das correlações entre esses enunciados situados nos domínios epistêmicos.

Nessa direção, o discurso "[...] de uma educação popular, que existe por oposição a uma suposta 'educação dominante' [...]" (BRANDÃO, 1981, p. 85), ganha status em toda a sua plenitude nesse campo de domínio. Isso se consolida, sobretudo, com os enunciados mobilizados nas reflexões freireanas. A Educação Popular constituiu-se em um referencial político, ético e epistêmico para a EJA nos últimos 50 anos. Isso se verifica devido ao fato de "[...] o pensamento pedagógico de Paulo Freire e sua proposta para a alfabetização de adultos inspiraram os principais programas de alfabetização e educação popular [...]" nesse país (BRASIL, 2001, p. 22). Nessa ordem do discurso, a Educação Popular emerge como uma das séries enunciativas que é constituída pelos seguintes signos: a cultura na perspectiva antropológica, os saberes populares, o diálogo e a conscientização.

conceito antropológico de cultura aciona noções que consideram "[...] o homem como um ser de relações, [e] se chega à distinção entre dois mundos - o da natureza e o da cultura" (BRANDÃO, 1981, p. 45). A matéria-prima da Educação Popular é justamente o conhecimento da cultura, no campo de domínio antropológico. Esse discurso opera a distinção entre cultura e erudição ou Belas Artes. Isso implica a ruptura de certos modos de situar a questão da cultura. É fundamental, nesse discurso, considerar e valorizar os variados modos de existência da cultura e levar em conta o papel dos jovens e adultos na produção de "[...] diferentes formas de cultura: a cultura letrada e a não letrada, o trabalho, a arte, a religião, os diferentes padrões de comportamento e a sociabilidade" (BRASIL, 2001 , p. 24).

Os saberes populares, por sua vez, agregam o discurso do reconhecimento e da valorização dos "saberes práticos" que jovens e adultos construíram ao longo de suas trajetórias pessoais e sociais. Eles são marcados por signos correlatos ao enunciado da experiência existencial: mundo do trabalho, família, igreja, sindicatos, embates políticos, feiras livres, bares, grupos de hip hop, galeras, rua, enfim, qualquer outro espaço social em que os sujeitos transitam, ganha status. Em cada um desses lugares, os saberes que circulam e são 
produzidos apresentam uma especificidade em seu modo de existir. Em outras palavras:

[...] quando fazem bicos, como calculam o material de que necessitarão para realizar uma tarefa, [...] a quem recorrem quando precisam mandar uma correspondência, [...] quais são as estratégias que eles usam quando fazem cursos de treinamento em serviço [...] [e assim por diante] (KLEIMAN, 1995, p. 57).

terceiro signo constitutivo da série enunciativa da Educação Popular é o diálogo. Longe de ser concebido como uma mera estratégia didática para a EJA, o diálogo é uma atitude mediadora das relações, um fenômeno humano de busca pela criticidade e pela libertação. "Os dialogantes 'admiram' um mesmo mundo; afastam-se dele e com ele coincidem; nele põem-se e opõem-se. O diálogo não é um produto histórico, é a própria historicização" (FREIRE, 1981 , p. 10). Ele acontece em torno de um objeto cognoscível, comum aos sujeitos cognoscentes: o mundo. É o estabelecimento da relação dialógica que cria as condições de cognoscibilidade desse objeto (FREIRE, 1981). Ele não se limita a expressar saberes, porque também é constituído enunciativamente de mediação e metodologia de apropriação e construção de saberes. Sua condução é um modo de existência dos saberes - o saber dialogar.

Por fim, a conscientização² humana não se situa apenas como uma finalidade para a EJA, mas também como uma conexão que articula todos os aspectos do processo educativo. Por exemplo: se o objeto de aprendizagem é a matemática, o educando conscientiza-se matematicamente; caso seja a escrita, o processo ocorre do mesmo modo, assim como os demais campos do saber. Enfim, sob o ponto de vista da Educação Popular, a conscientização, para ser dialógica, é, necessariamente, crítica, perpassa todo o campo dos saberes e transita nos domínios do conhecimento.

A série enunciativa do conhecimento é mais um artefato específico que constitui a função que é o objeto deste tópico - ele é o signo evocativo dos saberes que passam por um processo elaborado de produção. É demarcado, nesse discurso, como um produto resultante de uma ação intencional, mediado por metodologias. Trata-se da capacidade de explicar as propriedades de um dado objeto, e não, daquilo que quem explica acredita ou deseja que seja. Então, a relação entre a EJA e o conhecimento é constituída por meio de duas 
séries de signos: a pesquisa como via de produção do conhecimento científico na EJA e suas especificidades como objeto do conhecimento.

Nessa função enunciativa, a EJA configura um campo de pesquisa com sua problemática específica, distinta de outros campos educativos. Esse é o lugar enunciativo da "[...] análise racional e científica do problema da educação dos adultos [...]" (PAIVA, 1987, p. 290). Eis alguns modos de configuração da relação entre pesquisa e EJA: a docência associada à pesquisa; a investigação de experiências; o estudo dos seus fundamentos históricos, políticos e sociais; o reconhecimento acadêmico de determinados pesquisadores e grupos de pesquisa desse campo; a realidade existencial dos sujeitos como uma problemática (nesse meio, ganham status enunciativo as investigações de natureza antropológica, porque elas constituem outro conjunto de possibilidades para a produção do conhecimento em EJA. Uma delas é o que ficou designado como "investigação ou pesquisa do universo vocabular" dos sujeitos, a partir das experiências e dos escritos freireanos); e a crítica à própria racionalidade científica, convertida em autocrítica.

Ainda no campo de domínio do conhecimento, uma das condições de existência de um dado objeto é o seu caráter de especificidade. A EJA também está inserida nesse movimento. Em outras palavras, conhecer a EJA nos permite compreender, identificar e explicar suas particularidades, isto é, aquelas características que a fazem existir de um modo, e não, de outro. Ao contrário, é possivel mencionar somente os aspectos gerais, pertinentes a toda e qualquer prática educativa, ou a qualquer prática social, aumentando ainda mais seu grau de generalidade e aprofundando seu desconhecimento. Assim, conhecer é um ato fundamental para adentrar nas especificidades do objeto cognoscível. $\bigcirc$ desconhecimento das especificidades, das finalidades e das funções induz à utilização, por exemplo, de "[...] textos infantilizados e estereotipados, como os textos que comumente aparecem nas cartilhas e nos livros de leitura para [...]" as séries iniciais do Ensino Fundamental (BRASIL, 2001, p. 21 ).

Finalmente, a escavação confere visibilidade à série enunciativa dos saberes pedagógicos. Esse artefato oscila entre as demais regiões dos saberes e do conhecimento. Inicialmente, esses saberes estão vinculados ao enunciado das experiências educativas, marcadas pela ausência de uma sistemática ou campo pedagógico consolidado nos discursos hegemônicos. Mas esses saberes assumem o status de conhecimento e tornam-se referência para a formação acadêmica do pedagogo, ao se vincularem a outros campos de domínio, como 
a História, a Antropologia, a Psicologia, etc. Eis os seus signos constitutivos: a Didática, o Planejamento Educacional, as teorias da cognição humana e a alfabetização.

No Curso de Pedagogia, a Didática já é consolidada como uma disciplina que estrutura o discurso sobre o ensino. Quem percorre essa rede enunciativa se depara com alguns artefatos notáveis em outros "lugares" que preservam o enunciado da otimização do processo. É o discurso do desenvolvimento de métodos e técnicas precisas, para que a pessoa possa ser "[...] instruída em tudo o que diz respeito à vida [...] com economia de tempo e de fadiga, com agrado e com solidez" (COMENIUS, 2001, p. 5). Tudo é cuidadosamente pensado e milimetricamente preparado. Ao analisar a relação enunciativa entre a Didática e a EJA, identifica-se a afirmação de "outro tipo de prática". Na perspectiva da Educação Popular, está posto que, nelas, "[...] não se experimentava só um novo método, mas, através dele, um novo sentimento de Mundo, uma nova esperança no Homem" (BRANDÃO, 1981, p. 8). Devido ao caráter dialético desse discurso, o aspecto da transformação da realidade social, política e histórica ganha centralidade. Deve-se pensar em uma didática com metodologias e estratégias que possam, antes de qualquer coisa, 166 construir uma prática educativa que aponte para a transformação da história. Não se trata simplesmente de uma inovação metodológica. "Antes de fazer isso, ele [Paulo Freire] investiu aos brados com uma educação, contra outras" (BRANDÃO, 1981 , p. 15).

○ signo da Didática aciona o Planejamento Educacional, que não prescinde de seus aspectos gerais, presentes em qualquer outra modalidade educativa. Basicamente, os elementos são: os objetivos, a execução e a avaliação. No campo de domínio da EJA, porém, sem abrir mão das questões gerais, os objetivos precisam ser estabelecidos em constante diálogo com os saberes constitutivos dos jovens e dos adultos. Por exemplo, a crítica à "[...] tecnificação do campo propriamente educativo através do planejamento educacional" (PAIVA, 1987, p. 290) é contundente na relação enunciativa que envolve a EJA e a Educação Popular. Isso é expresso em alguns documentos que mencionam "[...] um estudo detalhado da realidade para o planejamento das atividades relativas à educação dos adultos" (PAIVA, 1987, p. 290). O Planejamento Educacional, no discurso da EJA, insere-se na relação entre saberes e conhecimento, por meio da reflexão sobre os objetos e o 
[... ] conteúdo programático da educação [que] não é uma doação ou uma imposição [...], mas a devolução organizada, sistematizada e acrescentada ao povo daqueles elementos que este the entregou de forma inestruturada (FREIRE, 1981, p. 98).

Ainda nessa série enunciativa dos saberes pedagógicos, há o signo da cognição humana, que envolve dois momentos: 1 - o ato de refletir, problematizar e especular a respeito dos processos mentais como algo anterior à Psicologia Cognitiva (o discurso clássico presente na Didática Magna); 2 - os enunciados da cognição humana, que ganham status no discurso científico la Psicologia Genética de J. Piaget, os estudos de L. S. Vygotsky, a Teoria da Aprendizagem Verbal Significativa formulada por D. P. Ausubell. Mas, ao se falar em psicogênese, em processos cognitivos e em psicologia do desenvolvimento ou da aprendizagem, há uma vinculação imediata ao desenvolvimento da cognição infantil, que negligencia os processos de aprendizagem de adultos. É possível constatar que os vestígios desses enunciados já estão presentes no discurso comeniano: "[...] durante a velhice, é demasiado tarde para instruir o homem, porque a inteligência e a memória estão já em regressão. [...] a formação do homem deve começar na primavera da vida [... ]" (COMENIUS, 2001 , p. 93-94). Porém "a partir de meados da década de 80, [Século XX] difundem-se entre os educadores brasileiros estudos e pesquisas sobre o aprendizado da língua escrita com base na Lingüística e na Psicologia [...]" (BRASIL, 2001 , p. 30-31/3. Isso possibilita o aparecimento dos debates sobre a cognição no campo de domínio da EJA.

Finalmente, a alfabetização, na condição de função enunciativa dos saberes pedagógicos, correlaciona-se à seguinte série de signos: "exame crítico", "leitura de mundo", "conscientização", "instrumento de luta política", "organização popular" e "problematização". Nessa direção, "Paulo Freire elaborou uma proposta de alfabetização de adultos conscientizadora, cujo princípio básico pode ser traduzido numa frase sua que ficou célebre: 'A leitura do mundo precede a leitura da palavra'" (BRASIL, 2001 , p. 24). Suas expressões designativas estão banhadas por uma dimensão política de base popular. Nesse discurso, a própria decisão "[...] de fazer a alfabetização é um ato político [...] [e supera a ideia de ser] um problema técnico pedagógico, não devendo, por isso, ser 'misturada com a política" (BRANDÃO, 1981, p. 86). Trata-se, como Freire pensou, de "[...] mostrar como alfabetizar visando à libertação" política das classes populares (BRANDÃO, 1981, p. 11). Para esse 
discurso, um método de alfabetização que afirma a neutralidade política é falacioso, porque, ao defender a adaptação dos indivíduos ao status quo, torna-se incoerente com seu princípio de neutralidade. Já um método crítico de alfabetização vai declarar-se politicamente engajado em um projeto de libertação, em suma, um Saber pedagógico crítico.

\section{A função enunciativa das posições de Sujeitos}

O conhecimento acerca dos jovens e dos adultos da EJA é constituído na condição de existência enunciativa do educador. Por essa razão, desconhecer os sujeitos da EJA é um interdito nesse posicionamento enunciativo do pedagogo, que opta por essa modalidade, tanto como campo de estudos quanto de atuação. Para se fazer um profissional da EJA, o pedagogo deve conhecer o educando em suas múltiplas dimensões, que transcendem a ideia de aluno. Nessa direção, a função enunciativa que posiciona os sujeitos nessa ordem discursiva é constituída por duas séries de enunciados: os educandos - jovens e adultos - e os pedagogos que optam pela EJA como campo de ałuação.

Em determinados discursos sobre a EJA, a figura do educando é

[...] retratada apenas em seus aspectos negativos - pobreza, sofrimento, injustiça [...]. Ocorre também a redução dos interesses ou das necessidades educativas dos jovens e dos adultos ao que thes é imediato, enquanto sua vontade de conhecer vai muito além (BRASIL, 2001, p. 29-30).

segundo modo de posicionar esses educandos agrega uma série de fatores de afirmação4 desses sujeitos. Esses elementos exaltam seu caráter de trabalhadores, detentores e produtores de saberes, disposição para aprender e estar em constante processo de libertação. Em geral, " [...] são donas de casa, balconistas, operários, serventes da construção civil, agricultores [...] são cidadãos e trabalhadores, que já estão integrados de um modo ou de outro em nossa sociedade [...]" (BRASIL, 2001, p. 41-43). Com base nessa segunda perspectiva, os educandos são posicionados enunciativamente a partir de três séries de signos: as perspectivas de desenvolvimento, as questões identitárias e algumas condições de existência enunciativa. 
No que se refere à série de signos perspectivas de desenvolvimento, os sujeitos da EJA estão situados de duas maneiras. Em primeiro lugar, são identificados como pessoas. Isso amplia o modo de se falar sobre eles, uma vez que reduzi-los a alunos da Educação Básica, que não estão na idade própria, equivale a precarizar esse entendimento. Na condição de pessoa, o educando da EJA é situado na perspectiva do desenvolvimento humano. Nesse discurso, o processo educativo deve ser conduzido para desenvolver os aspectos físicos, valorativos e cognitivos dos sujeitos. Já a construção de um processo educativo contextualizado especificamente com sua condição de trabalhador é a segunda perspectiva de desenvolvimento correlata aos educandos. Enunciativamente, é possível afirmar que isso conferirá um direcionamento específico às propostas educativas voltadas para os adultos: a problematização de questões como o desemprego, a exploração do trabalhador e a qualificação profissional e etc., que são elementos emergentes nessa pauta.

A segunda série de signos constitutiva dos educandos também está apoiada nas questões identitárias. Isso evoca certa complexidade na existência dos sujeitos da EJA, fazendo emergir algumas questões correlacionadas a esse signo e ampliar ainda mais as possibilidades enunciativas. Não é possível falar em uma identidade, mas em identidades distintas que tecem essa rede: os sujeitos da EJA (o negro, o índio, o idoso, o camponês etc.). Nesse ponto de emergência, a questão da mulher destaca-se em meio à diversidade de sujeitos. Ela aparece em contraposição aos discursos que legitimam o costume de "[...] enviar os filhos homens para estudar na capital do estado e manter as mulheres em casa, para ajudar nos trabalhos domésticos e na roça, até o aguardado momento do casamento [...]" (MAGALHÃES, 1995, p. 203). Em outras palavras, além das características dos outros sujeitos, no campo das classes sociais, raciais e regionais, esse sujeito agrega posições de mãe, esposa, dona de casa e trabalhadora, que vende sua força de trabalho nem sempre reconhecida socialmente.

A série de signos que aciona algumas condições de existência enunciativa dos sujeitos da EJA está formada da seguinte maneira: o analfabeto, o membro de uma família e o indivíduo em sua dimensão subjetiva. $\bigcirc$ primeiro está constituído em meio a uma oposição de ideias: como um acomodado, submetido a situações de privações materiais, que seriam consequência de sua própria ignorância; por outro lado, essas "[...] idéias preconceituosas sobre adultos analfabetos foram criticadas; seus saberes e capacidades foram 
reconhecidos" (BRASIL, 2001, p. 21) nos discursos sobre a EJA. Já em sua segunda condição de existência, o sujeito da EJA está situado no meio familiar e tem relações estabelecidas. Assim, ao processo educativo cabe "[...] contribuir para transformá-lo, seja atuando no seio do lar, sobre os filhos, seja nas suas relações mais extensas [...]" (BEISIEGEL, 1974, p. 97). A terceira condição de existência o enuncia como um indivíduo com suas dimensões subjetivas, relativas à trajetória de vida, possíveis de se constituírem como objetos de problematização pelo processo educativo, que deve primar pela "[...] recuperação da autoestima da identidade pessoal e cultural e o reconhecimento mútuo dos educandos [...]" (BRASIL, 2001, p. 174).

Nessa ordem discursiva, o pedagogo emerge como a outra posição de sujeito. Ele é situado enunciativamente como um profissional que está presente nas instituições escolares e nas não escolares. $O$ que vai determinar a necessidade do seu trabalho é a existência de um projeto educacional, independentemente do espaço. Seja no campo do ensino, como docente e gestor de projetos educativos e/ou da instituição escolar, ou como pesquisador do campo educativo, nos variados espaços onde atua, o pedagogo está situado como um profissional de presença necessária. Sua relação com a EJA mobiliza 170 tanto sua dimensão formativa quanto sua atuação profissional e está constituída pelas seguintes séries de signos: o enunciado da formação do pedagogo que opta pela EJA e as dimensões da atuação docente na EJA.

De acordo com o discurso presente no Curso de Pedagogia da UFPB/ Campus I (João Pessoa), o estudo aprofundado acerca da EJA, na formação de um pedagogo, é uma escolha feita pelo aluno de Pedagogia. Mesmo optando por esse campo, ele passa, necessariamente, por uma formação geral, que contempla os aspectos pertinentes ao profissional da Educação. Em outras palavras, trata-se de um conjunto de "[...] questões que devem estar presentes na formação de todos os educadores [bem como aqueles que elegeram a] [...] educação de pessoas jovens e adultas, [...]" como campo de estudos e atuação (BRASIL, 2005, p. 10). O objeto da formação do pedagogo é o fenômeno educativo em suas múltiplas dimensões, e a EJA é um desses aspectos, que poderá, ou não, ser aprofundado pelo discente.

A profissionalização do pedagogo, para atuar na EJA, aborda um conjunto de questões específicas, centrada em enunciados como: políticas públicas em EJA, sua dimensão política, histórica, filosófica, valorativa e metodológica, 
além das posições de sujeitos analisadas e descritas no início deste tópico. Isso se configura como

[...] uma exigência de justiça social, para que a ampliação das oportunidades educacionais não se reduza a uma ilusão, e a escolarização tardia de milhares de cidadãos não se configure como mais uma experiência de fracasso e exclusão (BRASIL, 2001, p. 14).

A docência em EJA é mais uma dimensão formativa do estudante que opta por essa modalidade, que contemplará a alfabetização e as séries/ciclos iniciais do Ensino Fundamental. É um enunciado de valorização da EJA e de seu docente. No final das contas, significa superar a lógica dos anos 1940, da "[...] irrisória gratificação oferecida aos professores, com a qual só era possível aliciar um corpo docente despreparado e incompetente" (PAIVA, 1987, p. 193).

Finalmente, a segunda série de signos - o pedagogo e as dimensões da atuação docente na EJA - aciona duas posições de sujeitos: o professor e o educador de jovens e adultos. Longe de ser uma relação de oposição, que exclui seu correlato, esse vínculo entre professor e educador constitui o pedagogo em sua articulação com a docência na EJA. Nesse jogo enunciativo, o educador agrega alguns elementos do professor, porém, em um movimento semelhante a uma espiral, ele o supera e traz uma série de elementos marcados por signos como criticidade, compromisso social, identidade popular e engajamento político.

Pode-se, então, afirmar que ser professor pressupõe, ao menos, os seguintes aspectos: 1) Estabelecer uma relação com os educandos - esse ponto está vinculado à necessidade de conhecer o aluno, em suas múltiplas dimensões e, até mesmo, de construir relações afetivas; 2) Conhecer os conteúdos escolares - envolve a competência de que o professor necessita frente à língua, às operações matemáticas e aos demais conteúdos pertinentes; 3) Dominar métodos e técnicas de ensino - esse é o conhecimento didático, os métodos mais apropriados para cada conteúdo, cada aluno e cada conteúdo, que consiste em organizar o saber de maneira adequada. Assim, conhecer o método implica saber o quê e como deve ser ensinado; 4) Opor-se à precarização do trabalho docente, que vê no voluntariado uma alternativa para os problemas educacionais. 
A posição de educador de jovens e de adultos, ao ser assumida pelo pedagogo, não rompe com a figura do professor, mas a amplia, redimensiona e acrescenta outras correlações enunciativas: conhecedor dos alunos/educandos, dos conteúdos, dos métodos e das técnicas; crítico à parte desses conteúdos métodos e técnicas, a determinado modelo de docência, educação e sociedade e tem clareza de suas funções. Diferentemente do professor que não assume a posição de educador, aquele que assume logo é identificado como "[...] educador problematizador, [que] re-faz, constantemente, seu ato cognoscente, na cognoscibilidade dos educandos" (FREIRE, 1981, p. 80). A problematização do conhecimento é um elemento que diferencia o educador de outros professores que não são. Trata-se de questionar, constantemente, sua própria prática educativa. Para ser educador, o professor deve ter consciência de que o conhecimento é permanentemente inacabado e deve conhecer os métodos, as técnicas e a si mesmo, embora saiba, também, que esse inacabamento nunca será uma posição estática. Enfim, a função do "[...] educador problematizador é de proporcionar com os educandos as condições em que se dê a superação do conhecimento no nível da 'doxa' pelo verdadeiro conhecimento, o que se dá no nível do 'logos'" (FREIRE, 1981, p. 80).

\section{Conclusões}

A pesquisa empreendida sobre o enunciado da EJA no Curso de Pedagogia da UFPB/Campus / (João Pessoa) identificou que o esquema geral do discurso investigado é constituído em três funções enunciativas: o direito à educação, os saberes e as posições de sujeitos na ordem do discurso em questão. Com base nos resultados e nas discussões ora apresentados, algumas conclusões são demonstradas a seguir.

Em primeiro lugar, é possível afirmar, em relação à função do direito à educação, que a proposta de síntese entre a instituição escolar e a EJA é a condição enunciativa, por excelência, de existência dessa função enunciativa. Isso porque o Direito constitui-se de maneira tridimensional (fato, valor e norma). No deslocamento discursivo do direito ao campo da Educação, as experiências educativas de jovens e adultos, ocorridas nos espaços não institucionais, equivalem ao fato. Enquanto as séries de signos como cidadania, libertação, diálogo, saberes populares e etc. são valores. A institucionalidade da EJA, por 
meio de sua ocupação no espaço escolar, tornou-se norma. Caso um desses três pilares seja derrubado, essa estrutura do direito será deformada, perderá suas configurações, será demolida. Se a escola não se reconfigura em função das características da EJA - o acúmulo gerado nos movimentos populares acolhendo-a como fato e valor, não é o respeito à norma isoladamente que vai garantir o direito. Isso implica reciprocidade do lado da EJA.

Em outras palavras, ao adentrar a EJA no esquema escolar, por mais que a instituição se reconfigure em função de seu acúmulo teórico e prático, não se trata mais de uma experiência educativa conduzida por educadores militantes sem formação acadêmica, embora possa ser acompanhada pelos movimentos populares. A EJA assume, então, o caráter de institucionalidade, subordina-se ao ordenamento jurídico educacional, passa a obedecer a um calendário e às metas estabelecidas, fica sujeita a processos avaliativos internos e externos, e os profissionais da educação passam a conduzir o processo, enfim, uma série de implicações institucionais modifica o caráter de experiência não escolar. Portanto, nem a escola será a mesma nem a EJA tampouco. Caso contrário, o direito à educação cai por terra, pois, ao menos, um dos três pilares - fato, valor ou norma - seria derrubado.

Já em relação à função enunciativa dos saberes, é possível afirmar que a concepção de prática educativa em EJA, mobilizada pela ordem do discurso presente no Curso de Pedagogia da UFPB/Campus I (João Pessoa), é a Educação Popular. Isso apresenta uma regularidade mais intensa na função enunciativa dos saberes, ao ponto de essa concepção aparecer como uma abordagem teórica e metodológica orientadora da EJA, ou seja, um artefato constitutivo da função enunciativa dos saberes. Isso tem implicações não apenas no enunciado da experiência educativa, mas também no próprio campo epistemológico da EJA. A própria concepção de uma linha de pesquisa em Educação Popular, em um programa de pós-graduação acadêmico, configura-se uma evidência disso. De semelhante modo, o enunciado da Educação Popular demarca território nos saberes pedagógicos porquanto questiona algumas séries enunciativas que interditam as possibilidades de o adulto aprender.

Quanto à função enunciativa, que demarca as posições dos sujeitos, é possível afirmar que essa ordem discursiva investigada interpela o pedagogo que passa por essa formação a assumir a posição de educador de jovens e adultos. Está se falando de um pedagogo que, além de assumir sua identidade profissional, assuma-se também como militante da causa da EJA nos espaços 
que ocupar - escolares ou não - tanto na condição de pesquisador quanto na de professor ou gestor educacional. Conhecer a ordem discursiva que posiciona os educandos da EJA é mais um aspecto fundamental para a constituição desse pedagogo: as perspectivas de desenvolvimento do educando, as questões identitárias e suas condições de existência. Isso está circunscrito como pressuposto básico da formação do pedagogo em EJA. É uma formação numa perspectiva antropológica, vinculada aos princípios da Educação Popular: diálogo, reconhecimento dos saberes populares e domínio do conceito antropológico de cultura.

Finalmente, vale reafirmar a relevância da Análise Arqueológica do Discurso como uma abordagem teórica e metodológica rica em possibilidades de investigação de enunciados correlacionados ao campo da educação e da EJA, sobretudo ao domínio específico da Educação Popular, uma vez que é demarcado epistemologicamente por abordagens investigativas centradas nas experiências educativas, ocorridas nos espaços populares. Esse campo precisa conhecer arqueologicamente o que se diz no âmbito dessas experiências ou a respeito delas. É imperativo se desenvolver uma consciência enunciativa em torno desses processos educativos que são promovidos pelos movimentos popu174 lares ou pelas instituições que fazem Educação Popular. Portanto, é possível e necessário analisar, cada vez mais, as possibilidades investigativas que a AAD oferece à Educação Popular.

\section{Notas}

1 A consulta ao PPP do Curso de Pedagogia da UFPB/campus I (Uoão Pessoa) direcionou a investigação aos seguintes documentos: Doc 1 - DCN para EJA (Res CNE/CEB 1/2000); Doc 2 - Lei 9394/96; Doc 3 - Parecer CNE/CP (05/2005); Doc 4 - Prop. Curricular para EJA, 200 1; Doc 5 - Res. CNE/CP O 1/2006. Esses documentos mencionaram outros textos relevantes à explicitação do objeto da pesquisa: Doc 1 (Parecer CNE/CEB 11 /2000b; Dec. de Hamburgo de 1997; COMENIUS, Didáctica Magna, publicada em 2001; Res. CNE/CEB 2/98; Res. CNE/CEB 3/98; Parecer CNE/CEB 4/98; Parecer CNE/CEB 15/98; Parecer CNE/CEB 16/99); Doc 3 (Parecer CNE/CP 03/2006); Doc 4 (Constituição Federal de 1988; Educação popular e educação de adultos, de 1983; O problema da Educação de Adultos, de 1945; Estado e educação popular, 1974; FREIRE, Paulo. Pedagogia do oprimido, publicado em 1981 ; BRANDÃO, Carlos Rodrigues. O que é o método Paulo Freire? publicado em 1981 e KLEIMAN, Angela. Os significados do letramento publicado em 1995). Embora tenham aparecido outros textos correlacionados à EJA, apenas os documentos acima citados foram efetivamente consultados no decorrer da pesquisa apresentada. 
Marcos Angelus Miranda de Alcantara | Erenildo João Carlos

2 Freire (1967) reflete sobre o processo de conscientização em quatro etapas: a consciência ingênua, que concebe apenas a existência bruta do ser humano. $O$ sujeito acha-se incapaz de intervir na história e transformá-la; a consciência intransitiva, uma segunda modalidade, na qual os sujeitos ainda estão apegados às necessidades mais imediatas, sem uma reflexão acerca das causas sociais; a consciência transitiva, que situa o homem acima dos interesses vegetativos, aumenta seu poder de diálogo; e a consciência crítica, que é a percepção dos fatores que determinam a história, capacita o sujeito a relacionar os fatos históricos para compreender os problemas cotidianos na transformação do tempo/espaço, com sua participação ativa.

3 Para aprofundar essa questão, consultar os estudos de Emília Ferreiro, Magda Soares e Tânia Moura.

4 elemento afirmação é uma contraposição ao primeiro modo de se posicionarem os jovens e os adultos na EJA. Trata-se de uma interlocução com as séries enunciativas da Educação Popular, localizadas no território arqueológico dos saberes.

\section{Referências}

ALCANTARA, Marcos Angelus Miranda de; CARLOS, Erenildo João. Análise Arqueológica do Discurso: uma alternativa de investigação na Educação de Jovens e Adultos (EJA). Intersecções: Revista de Estudos sobre Práticas Discursivas e Textuais, Jundiaí, v. 11 , n. 3, p. 59-75, nov. 2013. Disponível em: <http://www.anchieta.br/unianchieta/revistas/interseccoes/ultimas_edicoes.asp>. Acesso em: 15 nov. 2014.

ALMEIDA, Cláudia Cristina Medeiros de. A formação docente na Educação de Jovens e Adultos: uma análise discursiva. 2008. 158f. Dissertação (Mestrado em Educação) Programa de Pós-Graduação em Educação, Universidade Federal de Alagoas, Maceió, 2008. Disponível em: <http://capesdw.capes.gov.br/capesdw/resumo.htmle idtese=200 8526001012011 P5>. Acesso em: 30 nov. 2012.

ARRUDA, Soeli Aparecida Rossi de. Leitura e escrita na EJA: práticas enunciativo-discursivas no Ensino Médio. 2010. 248f. Dissertação (Mestrado em Estudos da Linguagem) - Programa de Pós-Graduação em Estudos da Linguagem. Universidade Federal de Mato Grosso, Cuiabá, 2010. Disponível em: <http://capesdw.capes.gov.br/capesdw/resumo. htmlęidtese=2010150001019008P2>. Acesso em: 23 nov. 2012.

AZEVEDO, Janete Maria Lins de. Implicações da nova lógica de ação do Estado para a educação municipal. Educação \& Sociedade, Campinas, v. 23, n. 80, p. 49-71, 2002. Disponível em: <http://dx.doi.org/10.1590/S0101-73302002008000004>. Acesso em: 11 set. 2012.

BEISIEGEL, Celso de Rui. Estado e educação popular. São Paulo: Pioneira, 1974. 
Política e educação popular: a teoria e a prática de Paulo Freire no Brasil. Brasília: Liber Livro, 2008.

BRANDÃO, Carlos Rodrigues. A educação popular e a educação de jovens e adultos: antes e agora. In: MACHADO, Maria Margarida (Org.). Formação de educadores de jovens e adultos: II Seminário Nacional. Brasília: Secad/MEC, UNESCO, 2008.

O que é o método Paulo Freire? 2. ed. São Paulo: Brasiliense, 1981.

BRASIL. Conselho Nacional de Educação. CEB n 11 de 10 de maio de 2000. Institui as Diretrizes Curriculares Nacionais para Educação de Jovens e Adultos. maio de 2000. Disponivel em: <http://portal.mec.gov.br/index.php?option=com_content\&view=article\&i $d=13252 \% 3$ Aparecer-ceb-2000\&catid=323\%3Aorgaos-vinculados\&ltemid=866>. Acesso em: 14 fev. 2013.

Educação para jovens e adultos: ensino fundamental: proposta curricular $-1^{\circ}$ segmento/coordenação e texto final (de) Vera Maria Masagão Ribeiro. São Paulo: Ação Educativa; Brasília: MEC, 2001 . Disponível em: <portal. mec.gov.br/secad/.../propostacurricular/.../propostacurricular.p...>. Acesso em: 26 jan. 2013.

Lei n 9.394, de 20 de dezembro de 1996. Estabelece as diretrizes e bases da educação nacional. Lei de Diretrizes e Bases da Educação-LDB. Brasília, DF, 1996. Disponível em: <portal.mec.gov.br/seesp/arquivos/pdf/lei9394_ldbn 1.pdf>. Acesso em: 21 jan. 2013.

Ministério da Educação e Desporto. Câmara da Educação Básica do Conselho Nacional de Educação. Parecer CEB 16/99. Diretrizes Curriculares Nacionais para a Educação Profissional de Nível Técnico. Disponível em: <http:// portal. mec.gov.br/index. php? option=com_content\&view=article\&id=13253\%3Aparecer-ceb-1999\&catid=323\%3Aorgaos-vinculados\&ltemid=866>. Acesso em: 14 fev. 2013.

Ministério da Educação. Conselho Nacional de Educação/Conselho Pleno. Reexame do Parecer CNE/CP no 5/2005, que trata das Diretrizes Curriculares Nacionais para $\circ$ Curso de Pedagogia. Parecer CNE/CP No 3/2006. Disponível em: <http://portal. mec.gov. br/index. php? option=com_content\&view=article\&id=12749\&ltemid=866>. Acesso em: 14 fev. 2013.

Ministério da Educação. Conselho Nacional de Educação/Conselho Pleno. Parecer CNE/CP: 05/2005. Diretrizes Curriculares Nacionais para o Curso de Pedagogia. Disponível em: <http://portal.mec.gov.br/cne/arquivos/pdf/pcp05_05.pdf>. Acesso: 9 jul. 2014. 
CANTANHEDE, Rosa Maria Pimentel. Currículo integrado do Projovem urbano: do discurso oficial às percepções dos educadores do Programa. 2011 3v. $162 f$. Dissertação (Mestrado em Educação) - Programa de Pós-Graduação em Educação, Universidade Federal do Maranhão, São Luís, 2011 . Disponível em: <http://capesdw.capes.gov.br/ capesdw/resumo.htmleidtese=20113120001010008P8>. Acesso em: 15 nov. 2012.

CARLOS, Erenildo João. A formação do discurso sobre a Educação de Adultos no Brasil: de 1890 a 1940. 2005. 342f. Tese (Doutorado em Educação) - Programa de Pós-Graduação em Educação, Universidade Federal do Ceará, Fortaleza, 2005. Disponível em: <http:// paedagogiumejc.blogspot.com.br/p/escritos.html>. Acesso em: 30 maio 2013.

COMENIUS, João Amós. Didáctica magna: tratado da arte universal de ensinar tudo a todos. Lisboa: Fundação Calouste Gulbekian, 2001. Disponível em: <www.ebooksbrasil. org/adobeebook/didaticamagna.pdf>. Acesso em: 6 nov. 2013.

DI PIERRO, Maria Clara. A educação de jovens e adultos no Plano Nacional de Educação: avaliação, desafios e perspectivas. Educação \& Sociedade, Campinas, v. 31, n. 112, p. 939-959, 2010. Disponível em: <htpp://dx.doi.org/10.1590/S010173302010000300015>. Acesso em: 11 set. 2012.

FOUCAULT, Michel. Arqueologia do saber. Tradução Luiz Felipe Beata Neves, 7. ed. Rio de Janeiro: Forense Universitária, 2008.

FREIRE, Paulo. Educação como prática da liberdade. Rio de Janeiro: Paz e Terra, 1967. Digitalizado. Disponível em: <forumeja.org.br> Acesso em: 26 fev. 2012.

Pedagogia do oprimido. 9. ed. Rio de Janeiro: Paz e Terra, 1981.

KLEIMAN, Angela Bustos. Os significados do letramento: uma nova perspectiva sobre a prática social da escrita. Campinas: Mercado das Letras, 1995.

MAGALHÃES, Izabel. Práticas discursivas de letramento: a construção da identidade em relatos de mulheres. In: KLEIMAN, Angela Bustos (Org.). Os significados do Letramento: uma nova perspectiva sobre a prática social da escrita. Campinas: Mercado das Letras, 1995.

MARQUES, Denise Travassos; PACHANE, Graziela Giusti. Formação de educadores: uma perspectiva de educação de idosos em programas de EJA. Educação \& Sociedade, Campinas, v. 36, n. 2, p. 475-490. 2010. Disponível em: <http://dx.doi.org/10.1590/ S1517-97022010000200004>. Acesso em: 11 set. 2012. 
MARQUES, Eliza Solange Vasconcelos. A especificidade da Educação de Jovens e Adultos no discurso curricular da Rede Municipal do Recife. 2010, $114 f$. Dissertação (Mestrado em Educação) - Programa de Pós-Graduação em Educação, Universidade Federal de Pernambuco, 2010. Disponível em: <http://capesdw.capes.gov.br/capesdw/resumo.html ?.idtese=20101425001019001P7>. Acesso em: 22 nov. 2012.

MATENCIO, Maria de Lourdes Meirelles. Analfabetismo na mídia: conceitos e imagens sobre o letramento. In: KLEIMAN, Angela Bustos (Org.). Os significados do letramento: uma nova perspectiva sobre a prática social da escrita. Campinas: Mercado das Letras, 1995.

PAIVA, Vanilda Pereira. Educação popular e educação de adultos. 2. ed. Rio de Janeiro: Loyola, 1987.

REALE, Miguel. Fundamentos do direito. 3 ed. São Paulo: Editora Revista dos Tribunais. 2 ed. ampl. 1998.

RUOTTI, William. A produção textual escrita na EJA: uma análise a partir dos estudos da análise crítica do discurso. 2008. 165f. Dissertação (Mestrado em Língua Portuguesa) Programa de Pós-Graduação em Língua Portuguesa. Pontifícia Universidade Católica de São Paulo. São Paulo, 2008. Disponível em: <http://capesdw.capes.gov.br/capesdw/resumo. htmle idtese=20081933005010022Pb>. Acesso em: 01 dez. 2012.

SANTOS, Ana Paula Rufino dos. Trabalho e maternidade: regularidades enunciativas do discurso da feminilidade no currículo da EJA e no currículo cultural da telenovela. 2011. 189f. Dissertação (Mestrado em Educação) - Programa de Pós-Graduação em Educação, Universidade Federal de Pernambuco, Recife, 2011. Disponivel em: <http://capesdw. capes.gov.br/capesdw/resumo. html?idtese=2011325001019001P7>. Acesso em: 19 jan. 2013.

SESI/UNESCO. Conferência Internacional sobre a Educação de Adultos. (V. 1997, Hamburgo, Alemanha): Declaração de Hamburgo: agenda para o futuro. Brasília. 1999. Disponível em: <unesdoc.unesco.org/images/00 12/00 $1297 / 129773$ porb.pdf>. Acesso em: 19 ago. 2013.

SILVA, Eduardo Jorge Lopes. O Fórum de Educação de Jovens e Adultos do estado da Paraíba: uma nova configuração em movimentos sociais. 2003. 168f. Dissertação (Mestrado em Educação) - Programa de Pós-Graduação em Educação, Universidade Federal da Paraíba, João Pessoa, 2003. Disponível em: <http://capesdw.capes.gov.br/ capesdw/resumo. htmlęidtese=20032682400101500 1 P4>. Acesso em: 30 maio 2013.

UIVERSIDADE fEDERAL DA PARAÍBA. Projeto Político-pedagógico. Centro de Educação. Curso de Pedagogia. João Pessoa/Paraíba, 2006. 
Me. Marcos Angelus Miranda de Alcantara Universidade Federal da Paraíba

Programa de Pós-Graduação em Educação Grupo de Pesquisa "A Educação de Jovens e Adultos: políticas, práticas e discursos no cenário brasileiro" E-mail | marcosmirandadealcantara@gmail.com

Prof. Dr. Erenildo João Carlos Universidade Federal da Paraíba | João Pessoa Departamento de Fundamentação da Educação

Programa de Pós-Graduação em Educação Líder do grupo de Pesquisa "A Educação de Jovens e Adultos: políticas, práticas e discursos no cenário brasileiro" E-mail | erenildojc@hotmail.com

Recebido 28 abr. 2014 Aceito 6 jul. 2014 